\title{
ESTADO NO CONFESIONAL Y LAICISMO
}

\section{Carlos Salinas Araneda*}

RESUMEN: Que un Estado se declare no confesional y declare el derecho de libertad religiosa no significa que tenga que adoptar una actitud de indiferencia o, peor aún, de rechazo a la vivencia religiosa de sus ciudadanos. El laicismo en su versión decimonónica es, pues, ajeno a la noción de Estado no confesional o Estado laico. El tema es abordado distinguiendo los derechos de libertad de pensamiento, de conciencia y religiosa, afirmando la autonomía de cada uno de ellos y definiendo el locus iuris del ateísmo, para analizar, seguidamente, los principios que han de orientar el actuar del Estado de cara a la vivencia religiosa de los ciudadanos como factor social, esto es, los principios de libertad religiosa, de laicidad o no confesionalidad, de igualdad y de cooperación.

Palabras Clave: Libertad religiosa - Libertad de conciencia - Libertad de pensamiento - Laicismo - Ateísmo - No confesionalidad del Estado.

\section{Non-CONFESSIONAL STATE AND SECUlarism}

ABSTRACT: The fact that a State might declare itself as non-confessional and ascribes to the right of religious freedom does not mean that it has to adopt an attitude of indifference or, even worse, of rejection to the religious experience of its citizens. Secularism, in its nineteenth century version, is then strange to the notion of non-confessional State or Secular State. The topic is raised making a distinction between the rights of freedom of thought, freedom of conscience, and religious freedom, reinforcing the autonomy of each one and defining the locus iuris of atheism, to later analyze the principles that shall orient the State's performance, facing the religious experience as a social factor, this is, the principles of religious freedom, of secularism or non-confessionalism, of equal rights and cooperation.

Profesor titular en la Facultad de Derecho de la Pontificia Universidad Católica de Valparaíso (Chile). Doctor en Derecho, Universidad Complutense de Madrid; Doctor en Derecho Canónico, Pontificia Universidad Santo Tomás, Angelicum, de Roma. Dirección electrónica: csalinas@ucv,cl

Trabajo presentado en el Seminario "Significado y sentido del laicismo" organizado por la Escuela de Derecho de la Universidad Católica del Norte, el 16 de noviembre de 2007, en su sede Coquimbo.

Fecha de recepción: 29 de noviembre de 2007.

Fecha de aceptación: 18 de enero de 2008. 
KEY WORDS: Religious freedom - Freedom of conscience - Freedom of thought - Secularism - Atheism - Non-confessionalism of the State.

SUMARIO: I. El derecho de libertad religiosa. 1. Libertad de pensamiento. 2. Libertad de conciencia. 3. Libertad religiosa. 4. Autonomía de la libertad religiosa frente a la libertad de conciencia y a la libertad de pensamiento. 5. Libertad religiosa y ateísmo. II. Principio de libertad religiosa y laicismo. 1. Principio de libertad religiosa. 2. Principio de laicidad o no confesionalidad del Estado. 3. Principio de igualdad religiosa ante la ley. 4. Principio de cooperación. III. A modo de resumen final. IV. Bibliografia.

Las relaciones entre el poder temporal y el poder espiritual en Chile se encauzaron jurídicamente, desde los primeros momentos del descubrimiento y la conquista, por el régimen de patronato, según el cual el Estado tenía determinados derechos sobre la Iglesia, derechos que había obtenido por especial concesión pontificia ${ }^{1}$. Producida que fue la independencia, el cauce jurídico por el que siguieron discurriendo las relaciones entre ambos poderes no cambió, es decir, siguió siendo el patronato, pero esta vez como un hecho unilateralmente asumido por el Estado de Chile sin que nunca le fuera concedido, aun cuando hubo legaciones enviadas a Roma con ese preciso objetivo ${ }^{2}$. Este régimen vino a terminar recién en 1925 cuando la Constitución aprobada ese año estableció lo que entonces se dio en llamar la "libertad de cultos". Se ponía así término al Estado confesional.

\section{EL DERECHO DE LiBERTAD RELIGIOSA}

Esta separación entre el poder espiritual y el poder temporal en Chile se hizo en un momento en que el derecho de libertad religiosa, si bien ya existía $^{3}$, no había alcanzado el desarrollo que obtuvo en los años siguien-

El tema ha sido abundantemente tratado por la historiografía. Una visión de conjunto con bibliografía, en DE LA HeRA, Alberto (1992). "El patronato y el vicariato regio en Indias". En Borges, Pedro (director), Historia de la Iglesia en Hispanoamérica y Filipinas (siglos XV-XIX). Madrid (España): Biblioteca de Autores Cristianos, t. 1, pp. 63-79; DE LA HeRA, Alberto (1992). "El regalismo indiano". En Borges, Pedro (director), Historia de la Iglesia en Hispanoamérica y Filipinas (siglos XV-XIX). Madrid (España): Biblioteca de Autores Cristianos, t. 1, pp. 81-97. Fue la legación de don Ramón Luis Irarrázabal (1846-1850) y la de don Manuel Blanco Encalada (1855).

3 Aparece consagrada en las dos declaraciones de derechos que se formularon como fruto de las dos revoluciones de fines del siglo XVIII, en Estados Unidos de Norteamérica y en Francia. La aparición en el siglo XIX de la teoría de los derechos subjetivos supuso para la libertad religiosa una mayor precisión en su conceptuación técnica, calificándosela como un derecho público subjetivo de libertad. 
tes, especialmente después de las grandes declaraciones de derechos humanos del siglo XX, de las Naciones Unidas ${ }^{4}$ y de los Estados americanos ${ }^{5}$. Es por lo que la doctrina chilena se limitó a consagrar el término "libertad de cultos" en cuya exégesis no se hacía mayor desarrollo, para solo poner de relieve la novedad que suponía la ruptura con el régimen anterior de confesionalidad. El análisis del mismo se hacía, por lo demás, conjuntamente con el derecho de libertad de conciencia y de pensamiento ${ }^{6}$, no faltando quien afirmara que el derecho de libertad religiosa era una subespecie del derecho de libertad de conciencia ${ }^{7}$. Y como, por expresa decisión de los constituyentes de 1980, en esta materia la nueva Constitución no quiso innovar, sino mantener en lo posible los mismos planteamientos de 1925, con la nueva Constitución la situación no varió mayormente hasta años recientes y no precisamente por vía de los constitucionalistas.

El desarrollo del derecho de libertad religiosa en la segunda mitad del siglo XX, sin embargo, ha permitido no solo explicitar sus contenidos sino que definir su autonomía respecto de las otras dos grandes libertades, la de conciencia y la de pensamiento, autonomía que no solo se perfila con claridad en la doctrina, sino que ha sido consagrado igualmente en documentos internacionales ratificados por $\mathrm{Chile}^{8}$, por lo que, en mi opinión,

La religión aparece ya mencionada en el documento constitutivo de la ONU, la Carta de las Naciones Unidas de 1945 (art. 1,3; art. 55c). La Declaración universal de los derechos bumanos, de 1948, recoge con claridad el derecho de libertad religiosa en términos que han constituido la base del tratamiento que la libertad religiosa ha recibido en documentos posteriores, tanto internacionales como regionales (art. 18). Como se trataba de una declaración importante pero sin fuerza vinculante, después de largos y complejos trabajos se adoptaron en 1966 el Pacto internacional de derechos económicos, sociales y culturales, y el Pacto internacional de derechos civiles y politicos, en que el tema de la libertad religiosa es nuevamente abordado, especialmente en el segundo (art. $18,4^{\circ} ; 4 ; 26 ; 27$ ).

$5 \quad$ En 1948, antes incluso de que se proclamara la Declaración universal de los derechos bumanos de la ONU, aunque influida pos sus trabajos preparatorios, la IX Conferencia internacional aprobaba la Declaración americana de los derechos y deberes del bombre, en la que el factor religioso es aludido especialmente en dos ocasiones (art. 3; 22; también art. 2). Como se trataba de un texto importante pero con un valor más bien moral, durante los años siguientes continuaron los esfuerzos para establecer un instrumento más eficaz de protección que llegaría en 1969 con la Convención americana sobre derechos bumanos o Pacto de San José de Costa Rica (art. 12).

6. Por ejemplo, Evans de la Cuadra, Enrique (1986). Los derechos constitucionales. Santiago: Editorial Jurídica de Chile, t. 1, 384 pp., p. 208.

7 "El señor Guzmán [Jaime]... Piensa que la libertad de conciencia es anterior, es no solo anterior a la manifestación de todas las creencias y al ejercicio de todos los cultos, sino que es también el fundamento de la libertad de opinión... Entiende que la libertad de manifestar las creencias religiosas deriva de la libertad de conciencia...". República de Chile, Actas oficiales de la comisión constituyente. Sesión $130^{\circ}$, celebrada en martes 17 de junio de 1975, 24 pp., pp. 11-12.

8 Por ejemplo, el art. 18.1 del Pacto internacional de derechos civiles y políticos (DO. 29 abril 1989), señala que "toda persona tiene derecho a la libertad de pensamiento, de conciencia y de religion". En los mismos términos se expresa el art. 14.1 de la Convención sobre los derechos del niño (DO. 27 septiembre 1990): "Los Estados Partes respetarán el derecho del niño a la libertad de pensamiento, de conciencia y de religión". Reconozco que es un tema que en materia internacional no ha tenido siempre la debida claridad, como sucede, por ejemplo, con el Pacto de San José de 
la autonomía de estas tres grandes libertades es posible afirmarla también en nuestro ordenamiento jurídico actual? .

\section{Libertad de pensamiento}

El rasgo típico de la libertad de pensamiento es la actividad intelectual en busca de la verdad o en la adopción de opiniones. "El derecho de libertad de pensamiento tiene por objeto el conjunto de ideas y juicios que el hombre tiene sobre las distintas realidades del mundo y de la vida, de acuerdo con las cuales obra en relación con sus fines naturales; más específicamente, pensamiento quiere decir aquí la concepción sobre las cosas, el hombre y la sociedad, que cada persona posee y de acuerdo con el cual actúa: pensamiento filosófico, cultural, científico, político, artístico, lúdico, etc. Por lo dicho se observa que no se trata de una libertad limitada al conocimiento especulativo y a su transmisión o manifestación. Engloba el entendimiento práctico y comporta la libertad de obrar y de conducirse de conformidad con el propio pensamiento. Es un libertad de pensar, pero también de obrat" 10 .

Así entendido el derecho de libertad de pensamiento, impone al Estado un principio de actuación según el cual carece de competencia para elaborar, mantener e imponer, cual si fuera un Estado sustituto del ámbito de racionalidad de sus ciudadanos, un pensamiento estatal oficial sobre la filosofía, la cultura, la ciencia, las teorías y sistemas políticos, el arte y, en suma, la concepción del hombre, del mundo y de la vida. La única misión del Estado en este campo le vendrá dada al "ponerse al servicio" del reconocimiento y garantía de la libertad de pensamiento de sus ciudadanos. Y servir -no sustituir, violar o coaccionar- se traducirá en una actividad jurídica reguladora del ejercicio social de tal derecho, regulación fundada en que tal derecho es innato de la persona y no una concesión de los poderes públicos ${ }^{11}$.

\section{Libertad de conciencia}

"Conciencia es el dictamen de lo que moralmente puede hacerse u omitirse en una situación concreta en la que se encuentra el hombre. El

Costa Rica, pero reconozco también que en los últimos años la terminología utilizada ha ido perfilándose con más claridad, como lo muestran los dos tratados que acabo de mencionar. Ediciones Universitarias de Valparaíso de la Pontificia Universidad Católica de Valparaíso, 474 pp., pp. 88-100.

10 Hervada, Javier (1984) "Libertad de conciencia y error sobre la moralidad de una terapia". Persona y Derecho, vol. 11, pp. 13-53, p. 35.

11 Viladrich, Pedro Juan (1980) "Los principios informadores del derecho eclesiástico español”. En González del VAlle, José María et alii, Derecho eclesiástico del estado español. Pamplona: Eunsa, pp. 211-317, pp. 265-266. 
rasgo fundamental de la conciencia reside en que aparece en la acción singular y concreta. No consiste en enunciados generales, sino en el juicio del deber respecto de la conducta concreta que el sujeto está en trance de realizar -conciencia antecedente-, está realizando -conciencia concomitante-, o ha realizado -conciencia consiguiente- que se manifiesta en satisfacción o remordimiento" 12 .

En otras palabras, la conciencia es un juicio personal sobre la "moralidad" de la acción singular y concreta que se presenta como posibilidad o como algo haciéndose o ya hecho. Por eso, solo de la persona singular se predica la conciencia, de donde la libertad de conciencia, como lógica consecuencia, tiene como titular solo a personas singulares y nunca a comunidades.

A la luz de lo anterior, el derecho que garantiza la libertad de conciencia hace referencia al juicio moral sobre las propias acciones y a la actuación en conformidad con dicho juicio moral. El objeto de este derecho es el juicio de moralidad y la actuación en consonancia con ese juicio. La libertad de conciencia, por tanto, protege la libertad fundamental de todo ciudadano, como persona, en la búsqueda del bien, de poseer su propio juicio moral como acto personal de la conciencia y en adecuar sus comportamientos y realizar su vida según el personal juicio de moralidad.

Un ejemplo nos puede aclarar esto: un objetor al servicio militar por simples motivos pacifistas no está poniendo en juego la libertad de conciencia, sino la libertad de pensamiento; en cambio el objetor que lo hace por estimar que la guerra es siempre inmoral, está poniendo en juego la libertad de conciencia. Cuando nos encontramos con un vegetariano que no come carne por considerarla perjudicial para la salud y por pensar que el hombre no es carnívoro, nos enfrentamos a un caso de libertad de pensamiento; pero cuando un musulmán no come carne de cerdo, estamos ante un caso de libertad de conciencia.

En otras palabras, "el Estado de ciudadanos-libres, en consecuencia, es en su raíz, en su esencia como Estado, absolutamente incompetente para señalar qué es el bien y qué el mal, cuál es la moral, la ética y las creencias sobre moralidad que deben seguir sus ciudadanos"13.

\section{Libertad religiosa}

Para abordar esta específica libertad, menester es precisar lo que vamos a entender por religión. En otra sede me he referido a la inexistencia de un concepto jurídico de religión a pesar de los esfuerzos que se han

\footnotetext{
12 HerVada (1984) 42-43.

13 VILADRICH (1980) 267.
} 
hecho en ese sentido ${ }^{14}$. De los tres sentidos fundamentales de la palabra religión -virtud, relación con Dios, comunidad religiosa- me interesa el segundo, según el cual la libertad religiosa tiene por objeto el sistema de relación del hombre con Dios en cuanto tiene una proyección externa, esto es, una práctica, enseñanza, culto, observancia ${ }^{15}$.

Ahora bien, lo que defiende y ampara el derecho de libertad religiosa no es la idea acerca de Dios y su existencia. La religión es la relación vital del hombre con Dios. Si bien esta relación vital supone un credo religioso y conlleva una moral, el núcleo central de la religión es el diálogo entre el hombre y Dios. "Si no hay una relación dialógica, sino la captación de que Dios existe, pero sin diálogo con el hombre, como es el caso de las concepciones panteístas o de las llamadas teístas, no hay religión propiamente dicho, sino 'cosmovisión deísta' (libertad de pensamiento), aunque el hombre invoque a veces a Dios. En este sentido, por ejemplo, el budismo más que una religión es una filosofía, pese a que presente rasgos similares a las religiones y a que habitualmente se le tenga por tal" 16 .

Puesto que la religión es una relación dialógica, la religión solo puede darse si se admite una manifestación o revelación de la divinidad que inicia el diálogo, revelación que puede ser natural -Dios se manifiesta a través de las criaturas-o sobrenatural -Dios habla por sí a los hombres o a través de enviados-. Como la revelación de la divinidad puede ser natural o sobrenatural, la respuesta del hombre a esta apelación dialogal puede ser una respuesta de razón -religión natural-o de fe -religión sobrenatural-.

Conforme a lo anterior, lo protegido primordialmente por la libertad religiosa es el acto de adhesión a Dios en una relación dialogal, la respuesta libre del hombre a la invitación de Dios. Ahora bien, como lo protegido por la libertad religiosa es la respuesta del hombre a la invitación de Dios a dialogar con Él, esa respuesta humana puede ser afirmativa o negativa, de donde se deduce que lo protegido por la libertad religiosa no es solo el acto positivo de adhesión, sino que la libertad religiosa significa que todo hombre debe estar inmune de coacción tanto para realizar el acto de adhesión a Dios y vivir en consecuencia, como para no realizarlo. En este sentido, y solo en este sentido, los fenómenos del ateísmo y del agnosticismo son también objeto de libertad religiosa, como veremos.

Con todo, el acto fundamental de adhesión a Dios, si bien constituye el objeto primordial de la libertad religiosa, no lo agota, pues dicha adhe-

Salinas Araneda, Carlos (2001). Sectas y derecho. La respuesta juridica al problema de los nuevos movimientos religiosos. Valparaíso: Ediciones Universitarias de Valparaíso de la Universidad Católica de Valparaíso, 417 pp., pp. 29-91; Salinas Araneda, Carlos (2001-2002). "Confesión religiosa: los intentos hacia un concepto jurídico". En Liberta religiosa e ordinamenti democratici, volumen especial de Religione e sette nel mondo, vol. 22, pp. 75-129.

15 HeRVADA (1984) 38.

16 HeRVADA (1984) 38. 
sión conlleva la práctica religiosa, de culto, de observancia, de enseñanza. Es por lo que la libertad religiosa implica también la libertad de las comunidades religiosas: autonomía normativa, culto colectivo en privado y en público, atención religiosa a los miembros, elección, nombramiento y traslado de ministros, uso de bienes muebles e inmuebles, divulgación de la doctrina, reuniones, formación de asociaciones, etc.

El derecho de libertad religiosa tiene, en consecuencia, por objeto la fe -en la doble dimensión de acto de fe y de contenido de dicho acto de fe- y la práctica de la religión en todas sus manifestaciones, individuales, asociadas o institucionales, tanto públicas como privadas, con libertad para su enseñanza, predicación, culto, observancia y cambio de religión y de profesión de la misma. Es lo que se denominan los dos momentos de la libertad religiosa: el primero implica la libertad para hacer el acto de fe o negarse al mismo; el segundo, la libertad para, supuesta la respuesta afirmativa al acto de fe en el primer momento, poder actuar conforme a dicho acto de fe, realizando los actos de culto que implica la fe que se profesa.

\section{Autonomía de la libertad religiosa frente a la libertad de con- ciencia y a la libertad de pensamiento}

Por de pronto, conviene señalar que estos tres derechos presentan aspectos comunes. Su denominador común se encuentra en su raíz: "las tres implican el reconocimiento de la naturaleza y dignidad del ser personal de cada ciudadano en su dimensión más profunda y específica, a saber, aquella donde la persona es y actúa el carácter innato, inviolable, irrenunciable e imprescriptible de su racionalidad y de su conciencia mediante la búsqueda y el establecimiento, por sí y sin ningún género de coacción o sustitución, de su propia relación con la verdad, el bien, la belleza y Dios" ${ }^{17}$.

Este común denominador explica, por una parte, la tendencia de los textos internacionales y constitucionales de reconocer conjuntamente y, a veces, en un mismo precepto, la libertad de pensamiento, de conciencia y de religión. Pero también explica, por otra parte, que estas tres libertades se confundan, considerándose muchas veces la fe como un ejemplo más de pensamiento o de conciencia moral, o simplemente una de las expresiones de la libertad de conciencia. Tiende a favorecer esta confusión el observar que la fe religiosa conlleva, para el sujeto que la profesa, una concepción del hombre, del mundo y de la vida -una Weltanschaunng o visión explicativa del conjunto del cosmos- y también una ética e, incluso, una estética.

Es cierto que la religión, en la mayoría de los casos, lleva aparejada una concepción global del hombre, del mundo y de la vida y, además, todo un sistema ético o moral. Pero también es cierto que la fe, como acto per- 
sonal y sobre todo como religión, es en sí misma más que la ética o la concepción antropológica que se desprende de ella. Conforme a esto, una ética derivada de una fe religiosa es protegida no por la libertad religiosa, sino por la libertad de conciencia. Y la visión antropológica o cosmológica que traiga aparejada una religión, tampoco queda amparada por la libertad religiosa, sino por la libertad de pensamiento, de la misma manera que por esta libertad quedan protegidas aquellas Weltanschaunng que no arrancan de credo religioso alguno.

Lo anterior podemos decirlo de otro modo: la creencia en Dios -cualquiera sea el nombre que le demos- puede implicar una posición de la persona sobre la verdad, el bien y la belleza a partir de la fe religiosa que profesa; pero también se puede tener una actitud ante la verdad, el bien y la belleza adoptada al margen o con independencia de una fe religiosa. El tema de Dios es el objeto del derecho de libertad religiosa en el sentido de acto de fe y de profesión de la religión a través de todas sus manifestaciones. Mientras el tema de la actitud de la persona ante la verdad, el bien y la belleza, se derive o no de una postura religiosa, posee autonomía propia y es objeto de la libertad de pensamiento y de la libertad de conciencia.

Corolario de lo anterior es que "el sistema ideológico, el conjunto cultural y la moral, ya se deriven de una fe religiosa o de una posición agnóstica o de la profesión de un ateísmo sistemático y militante, no son objeto del derecho de libertad religiosa, sino del derecho de libertad de pensamiento y del derecho de libertad de creencias morales"18. En otras palabras, ideología y moral son objeto del derecho de libertad de pensamiento y del derecho de libertad de conciencia, respectivamente, con independencia de que tales ideologías o éticas sean de procedencia atea, agnóstica o confesional. Ese es su locus iuris. Cabe, sin embargo, preguntarse por el locus iuris del ateísmo, esto es, preguntarse si el ateísmo o el agnosticismo en tanto planteamientos frente al tema de Dios, quedan amparados por el derecho de libertad religiosa ${ }^{19}$.

\section{Libertad religiosa y ateísmo}

Es un hecho de nuestra sociedad chilena que hay quienes viven al margen de una confesión religiosa o, más aún, al margen de toda creencia religiosa ${ }^{20}$. Incluso, algunas personas desarrollan su negación a lo sobrena-

18

SALinas (2004) 95-100.

Según la información proporcionada por el censo de 2002, en Chile hay 581.546 hombres que no tienen ninguna religión o se declaran ateos o agnósticos; en las mismas condiciones hay 350.444 mujeres, lo que da un total de 931.990 personas, que representan el $8,30 \%$ de la población chilena actual. SaLiNas (2004) 100-105. 
tural constituyendo un sistema ateístico activo que, con un proselitismo semejante al religioso, difunde sus doctrinas y convicciones. Pues bien, ¿el agnosticismo y el ateísmo son manifestaciones amparadas por el derecho de libertad religiosa en igualdad de condiciones con las opciones fideísticas? Si, precisamente, el ateísmo es la negación de la existencia de Dios ¿puede ser considerado una manifestación del factor religioso reconocida y protegida por el derecho de libertad religiosa? En esta materia, como en tantas otras, el acierto en la respuesta acostumbra ir más unido al gusto por el matiz que por el simplismo.

La libertad religiosa, lo hemos visto recién, supone dos momentos: el primero, la libertad del acto de fe; el segundo, la práctica de la religión a que ese acto de fe da lugar, esto es, la libertad de culto religioso, tanto individual como asociada, y también institucional, ya pública como privada, con libertad para su enseñanza, predicación, observancia, culto y cambio de religión.

Si nos situamos en el primero de estos momentos, si a una postura agnóstica o atea le quitamos su correlato ideológico-cultural o ético, los que están protegidos por la libertad de pensamiento, el primero, y de conciencia, el segundo, le resta el reconocimiento y la protección de la libertad del acto de fe, el que, en estos dos casos se resolverá en la no creencia -agnosticismo- o en la negación positiva de Dios -ateísmo-. Aunque en ambos casos la respuesta ante el tema de la fe es de contenido negativo, la libertad para tomar una tal postura queda amparada por el derecho de libertad religiosa el que, precisamente, resguarda y garantiza, en un primer momento, la libertad para que el hombre se defina ante el acto de fe, cualquiera que sea el contenido que dé a esa respuesta; y queda amparada por la libertad religiosa porque refleja el respeto al ámbito de racionalidad y de conciencia personales en el que se opta ante el tema de Dios -acto de fe- inmune de toda coacción, con independencia del signo agnóstico, ateo o fideístico de tal opción.

¿Qué sucede con el agnosticismo y el ateísmo en el segundo momento protegido por el derecho de libertad religiosa, esto es, la práctica de la religión y el culto? La práctica del agnosticismo o el despliegue de la no creencia religiosa a que da lugar no es, por definición culto y práctica religiosa. De la misma manera, la práctica o el despliegue del ateísmo, en tanto que es negación positiva de toda religiosidad, no es ni culto ni práctica religiosa alguna. De donde se sigue que, al no ser el agnosticismo y el ateísmo ni culto ni práctica religiosa alguna, el despliegue de los contenidos de uno y otro no queda amparado por la libertad religiosa. En la medida que dichos contenidos supongan una concepción global de las cosas o ideología, quedarán amparados por el derecho de libertad de pensamiento; y en la medida que supongan una moral, quedarán amparados por el derecho de libertad de conciencia. Pero ni en uno ni en otro caso será el derecho de libertad religiosa su locus iuris. 
La ley 19.638, conocida como ley de entidades religiosas (1999), admite expresamente este planteamiento, distinguiendo los dos momentos del derecho de libertad religiosa a los que me estoy refiriendo, cuando establece en su artículo 6 que "la libertad religiosa y de culto, con la correspondiente autonomía e inmunidad de coacción, significan para toda persona, a lo menos, las facultades de: a) profesar la creencia religiosa que libremente elija o no profesar ninguna; manifestarla libremente o abstenerse de bacerlo; cambiar o abandonar la que profesaba". Nada dice, en cambio, en el artículo 7 en el que se reconocen "a las entidades religiosas" plena autonomía para el desarrollo de sus fines propios y se mencionan algunas de sus facultades.

A manera de resumen, el supuesto de los no creyentes y del ateísmo me parece que es contemplado en nuestra Constitución en tres grandes derechos: i) lo que el agnosticismo y el ateísmo tienen de ejercicio libre y propio del acto de fe, es un bien o valor reconocido por el derecho de libertad religiosa; ii) lo que contiene de sistema ideológico-cultural, queda reconocido y amparado por la libertad de pensamiento; iii) lo que contienen de sistema ético o moral, queda reconocido por la libertad de conciencia. En estos dos últimos casos, lo amparado es su libre manifestación, el vivir en consonancia con esas opciones, enseñarlas, difundirlas individual, asociada o institucionalmente, en público o en privado, etc.

\section{PRincipio de libertad Religiosa y Laicismo}

Hasta el momento hemos considerado la libertad religiosa como un derecho subjetivo, desde la perspectiva de la persona humana titular del mismo. Cabe, sin embargo, mirar la libertad religiosa desde otra perspectiva, en concreto desde el Estado, en tanto que la libertad religiosa es ahora uno de los principios que informan su actuar, en cuanto Estado, de cara a la dimensión religiosa de sus ciudadanos ${ }^{21}$.

Los principios informadores del Estado en relación con la dimensión religiosas de sus ciudadanos consisten en aquellos "valores superiores" que el pueblo chileno posee como patrimonio resultado de su historia, de su presente y de su proyección de futuro, acerca de la dignidad y libertad de todo ciudadano en cuanto persona y acerca del modo digno y libre de poder vivir el sentimiento y las convicciones religiosas como factor social.

Hablo de "valores superiores" que no hay que confundir con las concretas creencias religiosas o posturas agnósticas o ateísticas de los chilenos. En otras palabras, se trata de "valores" que son superiores en el plano de la

21 Sobre los principios informadores del derecho eclesiástico del Estado de Chile: SALINAS ARANEDA, Carlos (2002) "Los principios informadores del derecho eclesiástico del Estado de Chile". Revista de Derecho de la Universidad Católica de Valparaiso, vol. 23, pp. 79-137. Salinas (2004) 197-227. 
convivencia solidaria de todos los chilenos como única nación, por encima de las diversas y concretas convicciones religiosas de quienes integran esta única nación. Se trata, por ende, de "valores civiles" y nunca de valores religiosos, pues no plasman la concepción religiosa de la sociedad -cualquiera que ella sea, confesional, agnóstica o atea-, sino la regulación civil que el Estado de Chile ha de dar al hecho religioso por encima de las opciones religiosas personales que haga cada ciudadano. Es más, incluso en el evento de que estos valores superiores coincidan con los valores religiosos de la sociedad chilena, dichos valores seguirán siéndolo por ser de la sociedad civil y no por resultar de la mayoría sociológica que se manifiesta religiosamente de una determinada manera.

Al mismo tiempo, estos principios informadores se nos presentan como "claves de bóveda en las que se articula la ordenación jurídica de toda la multiplicidad de relaciones sociales que genera el factor religioso, de suerte que tal ordenación resulte operativa, coherente y sistemáticamente unitaria" 22 .

Los principios informadores del actuar del Estado de Chile en función de la dimensión religiosa de sus ciudadanos, en mi opinión son cuatro: i) el principio de libertad religiosa; ii) el principio de no confesionalidad del Estado, denominado por algunos el principio de laicidad del Estado; iii) el principio de igualdad; y iv) el principio de cooperación.

\section{Principio de libertad religiosa}

Cuando me he referido a la libertad religiosa como derecho fundamental, mi atención se ha centrado en un concreto derecho innato, inviolable, imprescriptible de toda persona humana por el solo hecho de ser persona humana que, junto con otros derechos, constituye el patrimonio jurídico básico y radical de la persona frente a la sociedad y al Estado. Desde esta perspectiva, la libertad religiosa como derecho fundamental contiene una idea o definición de persona.

En cambio, cuando me refiero a la libertad religiosa como principio informador, mi atención se centra en una característica del Estado el que queda estructurado de un modo -y no de otro- como resultado de responder a las exigencias conformadoras que surgen del principio. Desde esta perspectiva, la libertad religiosa contiene una idea o definición de Estado.

La libertad como principio informador del Estado en materia religiosa, visto positivamente, significa que el acto de fe es absolutamente ajeno a la naturaleza y a la identidad del Estado. No siendo el Estado sujeto personal no es sujeto del acto de fe porque, correspondiendo el acto de fe a la persona en el ámbito de la racionalidad y de la conciencia, el Esta- 
do deviene por naturaleza radicalmente incompetente no solo en orden a coaccionar, sino también a sustituir o concurrir en orden al acto de fe. En este sentido, el principio de libertad religiosa significa que la fe es libre de Estado.

Desde esta perspectiva se comprenderá que en el extremo contrario al del Estado que asume el principio de libertad religiosa como principio informador de su actuar, se encuentra el Estado confesional, es decir, aquel Estado que se considera competente para hacer el acto de fe y asume una religión como la oficial del Estado. De esta manera, Estado confesional y Estado de libertad religiosa son términos que se excluyen el uno al otro. O el Estado es competente para el acto de fe, y nos encontramos frente al Estado confesional; o el Estado asume como principio la libertad religiosa y, por lo mismo, se considera incompetente para hacer el acto de fe.

Sin embargo, el Estado no puede confundir su radical incompetencia ante el acto de fe con aquellas formas de resolver el acto de fe de contenido negativo, agnóstico, ateo o indiferente. Este es un matiz importante y que toca al núcleo de mi intervención. El Estado que decide ser ateo, agnóstico o indiferente -formas diversas del laicismo decimonónico- está considerándose competente para el acto de fe, puesto que definirse ateo, agnóstico o indiferente implica considerarse competente para enfrentarse al tema de la fe y resolverlo negativamente mediante un acto de ateísmo, de agnosticismo o de indiferencia.

Como resulta obvio, supuesto el principio de libertad religiosa, ninguna confesión o religión podrá ser asumida como propia por el Estado o, dicho en otras palabras, ninguna confesión tendrá carácter estatal. Pero tampoco tendrá carácter estatal el agnosticismo, el ateísmo o el indiferentismo por la simple razón de que el Estado es incompetente para el acto de $\mathrm{fe}$, ya sea que se dé a ese acto un sentido afirmativo -creo- o negativo -no creo-.

\section{Principio de laicidad o no confesionalidad del Estado}

Acabo de afirmar que el Estado, en cuanto Estado, es incapaz del acto de fe. He dicho igualmente que esa incapacidad no significa que el Estado tenga que hacer profesión de agnosticismo, de ateísmo o de indiferentismo, pues, asumiendo tales actitudes, el Estado se considera competente para hacer el acto de fe, solo que la respuesta al mismo es en sentido negativo.

Pues bien, la laicidad del Estado o, lo que es lo mismo, su no confesionalidad, significa que el Estado enfrentado a lo religioso como un factor social, ha de actuar solo como Estado. Surge, entonces, de inmediato la pregunta ¿qué es actuar solo como Estado en materia religiosa? ¿cuándo el Estado actúa solo como Estado ante el factor religioso y no como sujeto de fe, sea cual sea el contenido que se dé a ese acto de fe -confesional, ag- 
nóstico, ateo o indiferente-? "Si queremos sintetizar en pocas palabras el significado de la actuación no confesional del Estado o actuación solamente estatal, hemos de definirla como aquel tipo de actuación del Estado resultante de considerar lo religioso exclusivamente como factor social específico... cuando el Estado, al contemplar lo religioso, no ve otra cosa que un factor social que forma parte del conjunto de la realidad social y del bien común y que, con todas sus peculiaridades, es susceptible de reconocimiento, garantía y promoción jurídica, entonces dicho Estado no entra a definir lo religioso, en cuanto tal, sino como factor social y, en esa misma medida, lo capta y se sitúa ante él única y exclusivamente como Estado radicalmente incompetente ante la fe y ante lo religioso, como religioso, pero competente para regular jurídicamente un factor social más del bien común" 23 .

El Estado es laico, o sea no confesional, cuando contempla lo religioso no en cuanto religioso, sino en cuanto factor que forma parte de la realidad social y que, con todas sus peculiaridades, es susceptible de reconocimiento, garantía y promoción jurídicas. Así como el deporte y la cultura son factores sociales que el Estado debe reconocer y promover, no porque el Estado sea "deportista" o porque el Estado disfrute de la cultura, sino en cuanto son factores sociales, de la misma manera lo religioso ha de ser reconocido y regulado por el Estado pero no en cuanto religioso, sino en cuanto que es un factor social. De esta manera, el Estado al regular lo religioso no asume en ningún momento competencia alguna en cuanto al acto de fe, sino que, como Estado, asume el rol que como tal le corresponde, amparando y promoviendo aquellos factores sociales que forman parte del bien común y que el Estado, en cuanto Estado tiene que regular, como son el deporte, la cultura y lo religioso.

A la luz de lo anterior, que Chile sea un Estado laico, esto es, un Estado no confesional, está lejos de significar que haya de ser indiferente o incluso contrario a lo religioso. Que Chile sea un Estado laico, solo significa que ante lo religioso ha de actuar tan solo como Estado, regulando lo religioso no en cuanto religioso sino en cuanto factor social.

\section{Principio de igualdad religiosa ante la ley}

El artículo $19 \mathrm{n}^{\circ} 2$ de nuestra Constitución asegura a todas las personas "la igualdad ante la ley", al punto que "en Chile no hay personas ni grupos privilegiados... ni la ley ni autoridad alguna podrán establecer diferencias arbitrarias". Se trata de un principio genérico, cuyo natural correlato es la proscripción de cualquier clase de discriminación. Con esta afirmación, nuestra Constitución lo que hace es afirmar que en la base misma de la 
sociedad y del Estado hay una común y radical condición paritariamente poseída por todos y cada uno de los chilenos, cual es la cualidad de "ciudadano". La afirmación constitucional de la igualdad ante la ley, en otras palabras, no es sino la afirmación de que en Chile la existencia de diversas categorías de ciudadanos no es solo una conculcación profunda de un derecho subjetivo, sino que, peor aún, sería la negación de la esencia democrática del régimen político.

Si este genérico principio de igualdad ante la ley lo proyectamos a la religión, nuestra Constitución afirma la igualdad religiosa de todos los chilenos. Pero ello no significa, evidentemente, que todos los chilenos deban tener la misma religión, pues la igualdad religiosa no es sinónimo de uniformidad. En otras palabras, la igualdad religiosa ante la ley significa que la común y básica calidad de ciudadano de todos los chilenos comprende la titularidad del derecho de libertad religiosa en igualdad de calidad y trato ante la ley; dicho de otro modo, todos los chilenos somos "igualmente" titulares del "mismo" derecho de libertad religiosa.

Consecuencia de lo anterior, y como correlato a esta igualdad, queda excluida cualquier discriminación por razón de religión, de manera que está prohibida constitucionalmente cualquier distinción que, basada en motivos religiosos, persiga o consiga la supresión de la igualdad de titularidad o de ejercicio del derecho de libertad religiosa o su menoscabo respecto de los demás derechos fundamentales y libertades públicas. Lo dice expresamente la ley de entidades religiosas en su artículo 2: "Ninguna persona podrá ser discriminada en virtud de sus creencias religiosas, ni tampoco podrán éstas invocarse como motivo para suprimir, restringir o afectar la igualdad consagrada en la Constitución y la ley".

La igualdad, sin embargo, no significa uniformidad, como acabo de recordar. En efecto, "la igualdad ante la ley consiste en que las normas jurídicas deben ser iguales para todas las personas que se encuentran en las mismas circunstancias y que no deben concederse privilegios ni imponerse obligaciones a unos que no beneficien o graven a otros que se hallen en condiciones similares... la igualdad supone, por lo tanto, la distinción razonable entre quienes no se encuentren en la misma condición; por lo que ella no implica que la legislación contemple en forma distinta situaciones diferentes, siempre que la discriminación no sea arbitraria" 24 .

Así, la comprensión exacta de la igualdad religiosa es que todos los individuos y las confesiones, con independencia de sus características diferenciales, de su distinta tradición histórica o implantación sociológica, son, en tanto sujetos de libertad religiosa, iguales titulares del mismo derecho fundamental de libertad religiosa. 
Pero en el plano de la existencia, cada individuo y cada confesión ejercita, en la práctica, su irrepetible y específica singularidad, cada individuo o confesión despliega, en los hechos, su realidad diferencial. De donde se sigue que la igualdad radical como sujetos se traduce, en la cotidianeidad de la vida social, en un pluralismo libre.

De esta manera, no supone discriminación alguna el favorecimiento de una confesión religiosa si, de facto, ninguna otra confesión puede gozar de la misma prerrogativa, o si ninguna otra reúne los mismos requisitos que la favorecida. Cada confesión tiene sus propias características, y su propia forma de ver sus relaciones con el Estado, por lo que no se puede hacer lo mismo con todas sino que, atendiendo a sus peculiaridades, el Estado deberá adoptar posturas diferentes y específicas para cada cual. Es preciso, pues, atender a las especificidades de cada cual y en función de ellas definir la relación entre el Estado y la confesión de manera que, en las mismas circunstancias, el trato ha de ser el mismo, siendo discriminatorio el trato si, en igualdad de circunstancias, el trato es diferenciado. Pero no lo sería si las circunstancias para una y otra son diversas. Es por lo que no constituye una discriminación que la nueva ley de matrimonio civil permita que el matrimonio se celebre ante el ministro de culto de las entidades religiosas que gozan de personalidad jurídica de derecho público y lo niegue, en cambio, para las que no tienen esa calidad. Pero sí sería discriminatorio si el Estado negara esa posibilidad a los fieles de una entidad religiosa que sí tuviera personalidad jurídica de derecho público.

Un medio idóneo para obtener este trato específico han sido en el derecho comparado los acuerdos entre las confesiones religiosas y el Estado. Ello sucede en España ${ }^{25}$, en Italia ${ }^{26}$, en Alemania ${ }^{27}$ y recientemente ha sido admitida esa posibilidad en la nueva Constitución de Perú ${ }^{28}$. Lamen-

RUANO EsPINA, Lourdes (1996). "Los acuerdos o convenios de cooperación entre los distintos poderes públicos y las confesiones religiosas". Revista Española de Derecho Canónico, vol. 53, No 140, pp. 157-187; Fernández Coronado, A. (1991). "Los acuerdos del Estado español con la Federación de entidades religiosas evangélicas de España (FEREDE) y la Federación de comunidades israelitas (FCI). Consideraciones sobre los textos definitivos". Anuario de Derecho Eclesiástico Español, vol. 7, pp. 541-578. Una completa bibliografía sobre el tema en MARTínez Torrón, Javier (1999). Religión, derecho y sociedad. Antiguos y nuevos planteamientos en el derecho eclesiástico del estado. Granada: Comares, 272 pp. 76-86.

Miraveli, Cesare (a cura di) (1978), Le intese tra Stato e confesione religiose. Problema e prospettive. Milano: Giuffrè, 240 pp.

27 Rossell Granados, Jaime (1997). Los acuerdos del Estado con las Iglesias en Alemania. Madrid: Centro de Estudios Constitucionales, 136 pp. Rossell Granados, Jaime (1998). "El sistema de acuerdos Estado-Iglesias en la República Federal de Alemania su posición en el ordenamiento jurídico". En MARTínez TORRón, Javier (editor): La libertad religiosa y de conciencia ante la justicia constitucional. Actas del VIII Congreso internacional de derecho eclesiástico del estado. Granada: Comares, 905 pp., pp. 787-797; ZABALZA BAS, I. (1986). "Los concordatos y contratos Iglesia-Estado en el derecho eclesiástico alemán". Anuario de Derecho Eclesiástico Español, Vol. 2, pp. 333-349. 
tablemente en Chile, si bien durante la discusión de la ley de entidades religiosas la Iglesia Católica propuso esa posibilidad, ella fue rechazada por las entidades evangélicas y, finalmente, no fue aceptada.

\section{Principio de cooperación}

Cooperación es "el tipo de relación (ni unión ni incomunicación) que puede haber entre instituciones cuya naturaleza y finalidades son distintas y han de permanecer sin mezclarse" 29 . La no confusión entre el Estado y las entidades religiosas está garantizada por el reconocimiento que hace el Estado de las confesiones religiosas ${ }^{30}$ como instituciones específicas del factor religioso y sujetos colectivos del derecho de libertad religiosa. Y el punto de encuentro entre Estado y confesiones es, en palabras de nuestra Constitución, la promoción del bien común por parte del Estado, para lo cual ha de contribuir " a crear las condiciones sociales que permitan a todos $y$ cada uno de los integrantes de la comunidad nacional su mayor realización espiritual y material posible" (art. 1 inc. $4^{\circ}$ ).

De lo anterior aparece claro que las confesiones son valoradas constitucionalmente en una doble perspectiva: i) como sujetos colectivos del derecho de libertad religiosa; ii) las confesiones no están incomunicadas con el Estado en aquella dimensión de su obrar que guarda directa relación con el servicio al desarrollo integral de los ciudadanos y del bien común.

De esta manera, el principio de cooperación significa el común entendimiento bilateral o plurilateral, que han de tener las relaciones entre los poderes públicos y las confesiones en orden a la elaboración de su estatus jurídico específico y a la regulación de su contribución al bien común ciudadano. En todo caso, una vez que el Estado decide que es oportuno cooperar con una determinada confesión, el principio de igualdad no le obliga a establecer ni el mismo tipo de cooperación, ni al mismo nivel con todas las confesiones con las que se relaciona. Precisamente, como ya lo he señalado, si algo no significa el principio de igualdad es "uniformidad", y si algo lo vulneraría sería tratar a todos los sujetos religiosos colectivos de la misma manera, sin apreciar sus especificidades.

Desde 1925 ha habido en Chile una innegable cooperación entre el Estado de Chile y las confesiones religiosas, la que ha adoptado diversas modalidades, la principal de la cuales, quizá, ha sido la cooperación económica, siendo la más frecuente la de las exenciones tributarias, ya de carác-

mia, el Estado reconoce a la Iglesia católica como elemento importante en la formación bistórica, cultural y moral del Perú, y le presta su colaboración. [inc. $2^{\circ}$ ] El Estado respeta otras confesiones y puede establecer formas de colaboración con ellas".

29 VILADRICH (1980) 307.

30 La ley 19.638 (1999) de entidades religiosas habla de "iglesias", "confesiones" o "entidades religiosas". 
ter general, como la establecida en la misma Constitución respecto de los templos y sus dependencias destinadas exclusivamente al servicio de un culto; ya de carácter específico, beneficiando a algunas entidades religiosas en particular precisamente por el porte que, con algunas de sus obras, hacen a la realización espiritual y material de los chilenos, como el Hogar de Cristo o la Obra filantrópica y de ayuda social adventista (Ofasa). Largo sería enumerar aquí, y no es este el lugar, las numerosas normas que se han dictado desde 1925 sobre esta materia, pero ellas muestran de manera inequívoca que la libertad religiosa proclamada en 1925 no significó un repliegue del Estado respecto de lo religioso ni un desconocimiento de la existencia y de la labor de las confesiones religiosas.

Por cierto que la cooperación no solo es económica, sino que ha de plantearse en todo aquello exigido para la realización del derecho de libertad religiosa. Así, en otro orden de ideas puede mencionarse la presencia de la religión en la enseñanza y la aprobación de los programas de religión presentados por diversas confesiones ${ }^{31}$, aceptando de esta manera, el Estado de Chile, el aporte específico que las confesiones pueden brindar en orden a perseguir la mayor realización espiritual y material de la persona ${ }^{32}$.

Hemos de tener presente que la cooperación del Estado no se limita tan solo a las confesiones religiosas, sino que se extiende también a muchas otras entidades que desarrollan actividades no religiosas, como la ópera, la música o el deporte, cooperación que tiene su fundamento en la demanda social de esas actividades. Parece claro que nadie podría considerar que la cooperación del Estado hacia el deporte supone un agravio a quienes no disfrutan del mismo o no lo practican. De la misma manera, el Estado coopera para que los ciudadanos que lo deseen puedan realizar sus prácticas religiosas. En suma, el Estado de Chile no relega a las confesiones religiosas a la esfera privada, ni entiende la separación entre el Estado y las Iglesias como un desconocimiento o indiferencia hacia las mismas; por el contrario, adopta una actitud positiva y activa ante ellas. Pero como se trata de la cooperación de un Estado no confesional, no ha de circunscribirse a una confesión determinada, sino que ha de dirigirse a tutelar todos aquellos grupos en los que se manifiesten las creencias de Ios chilenos en tanto no vayan contra el orden público constitucional; y en el entendido que coopera con ellos en cuanto son una realidad social contemplada por

31 Salinas (2004) pp. 113-114. Orrego Olmedo, Karem Andrea (2007). Estatuto juridico de la enseñanza religiosa en Chile. Valparaíso: Tesina Escuela de Derecho Pontificia Universidad Católica de Valparaíso, Director C. Salinas Araneda, inédita, 155 pp.

32 También pueden citarse ejemplos recientes como la Comisión Valech o las facilidades para que ministros de culto puedan ser informados sobre lugares en que se encuentran enterrados detenidos desaparecidos, o recibir armas en condiciones irregulares para ser posteriormente entregadas al Estado. 
la norma suprema y no porque sea mejor o peor encuadrarse en un grupo religioso institucionalizado.

Finalmente, los poderes públicos a la hora de cooperar, no han de entrar a cuestionar los contenidos fideísticos de las confesiones, sino su inserción en la sociedad chilena como hecho social, que es, en definitiva, lo que el Estado debe proteger y regular jurídicamente. Serán las especificidades de ese hecho social las que determinen la cooperación, su alcance y la modalidad de la misma. En este sentido, me parece claro que la Iglesia Católica tiene el mismo grado de libertad religiosa que las demás confesiones, pero por su mayor -e indiscutible-implantación social en Chile, precisa de un mayor nivel de cooperación en los diferentes ámbitos en los que participa. Sería una discriminación que, siendo la confesión mayoritaria y cubriendo más campos susceptibles de afectación social que las demás, se cooperase con ella en igual o menor medida que con las otras.

\section{A MODO DE RESUMEN FINAL}

El tema del laicismo en relación con el Estado, para comprenderlo adecuadamente, hay que situarlo en el contexto más amplio del derecho de libertad religiosa y de los principios que han de informar al Estado en su relación con la religiosidad de los ciudadanos en cuanto factor social. Es por lo que he querido en esta primera exposición, hacer una presentación somera de los mismos.

El laicismo, sin embargo, en su formulación decimonónica es un hecho que no ha desaparecido. Peor aún, el carácter agresivo que está presentando en algunos lugares permite hablar ya de un fundamentalismo laicista. La consecuencia que ello acarrea es que el concepto democrático de la laicidad del Estado que, como he tratado de exponer, es justo, se está transformando en otro muy diferente: precisamente el del fundamentalismo laicista. Las consecuencias pueden ser graves, especialmente en ámbitos como el de la familia, la educación o la juventud. Algunos proyectos legislativos y prácticas ministeriales que nos muestra el derecho comparado y nuestro propio país no solo son contrarios a la moral católica y de otras religiones, sino también contrarios a la ética natural y al mismo concepto jurídico laico de bien común.

No son el Estado, ni la Santa Sede, ni la Conferencia Episcopal, ni ninguna otra confesión, los copropietarios de la libertad religiosa, sino el ciudadano, cada uno de nosotros en singular. A este ciudadano, a su fe religiosa y al libre ejercicio de su culto es al que tiene que servir el Estado y los poderes públicos. Ninguna confesión puede tener carácter estatal, pero tampoco ninguna ideología. Es inconstitucional que el Estado patrocine una ideología laicista como la oficial de los poderes públicos. Cada 
ciudadano, a título particular, puede adoptarla y practicarla. Pero, si ocupase un cargo o poder público, no puede convertir esa ideología particular en la posición oficial del Estado. "Esa transferencia de la subjetividad ideológica laicista, de la visión agnóstica o atea de la fe religiosa, y su conversión en doctrina oficial de los poderes públicos y del Estado es -digámoslo con toda claridad- un atentado directo y gravísimo al derecho de libertad religiosa de cada ciudadano. Y es una muestra de dictadura ideológica" 33 .

En suma, si quisiéramos expresar en un brocardo todo lo que he dicho, podríamos formularlo así: "un Estado laico sin laicismo de Estado" 34 .

\section{BiBLIOGRAFÍA}

- Hervada, Javier (1984). "Libertad de conciencia y error sobre la moralidad de una terapia”. Persona y Derecho, vol. 11, pp. 13-53.

- Orrego Olmedo, Karem Andrea (2007). Estatuto jurídico de la enseñanza religiosa en Chile. Valparaíso: Tesina Escuela de Derecho Pontificia Universidad Católica de Valparaíso. Director, C. Salinas Araneda, inédita.

- República de Chile, Actas oficiales de la comisión constituyente. Sesión $130^{\circ}$, celebrada en martes 17 de junio de 1975 .

- Salinas Araneda, Carlos (2001). Sectas y derecho. La respuesta jurídica al problema de los nuevos movimientos religiosos. Valparaíso: Ediciones Universitarias de Valparaíso de la Universidad Católica de Valparaíso.

- _ (2001-2002). "Confesión religiosa: los intentos hacia un concepto jurídico". En Liberta religiosa e ordinamenti democratici, volumen especial de Religione e sette nel mondo, vol. 22, pp. 75-129

- (2002). "Los principios informadores del derecho eclesiástico del Estado de Chile". Revista de Derecho de la Universidad Católica de Valparaíso, vol. 23, pp. 79-137.

- (2004). Lecciones de derecho eclesiástico del Estado de Chile. Valparaíso: Ediciones Universitarias de Valparaíso de la Pontificia Universidad Católica de Valparaíso.

- Scola, cardenal Angelo (2007). Una nueva laicidad. Madrid: Ediciones Encuentro y Ceu Ediciones.

33 Viladrich, Pedro Juan (2007). "Libertad religiosa y Estado laicista". Palabras 518, 60 pp., p. 12.

34 SCOLA, cardenal Angelo (2007). Una nueva laicidad. Madrid: Ediciones Encuentro y Ceu Ediciones, 180 pp., p. 23. 
- Verdugo Marinkovic, Mario Pfeffer Urteaga, Emilio Nogueira Alcalá, Humberto (1994). Derecho constitucional. Santiago: Editorial Jurídica de Chile.

- Viladrich, Pedro Juan (1980). "Los principios informadores del derecho eclesiástico español". En González del Valle, José María et alii, Derecho eclesiástico del estado español. Pamplona: Eunsa, pp. 211-317.

518.

(2007). "Libertad religiosa y Estado laicista". Palabras, 